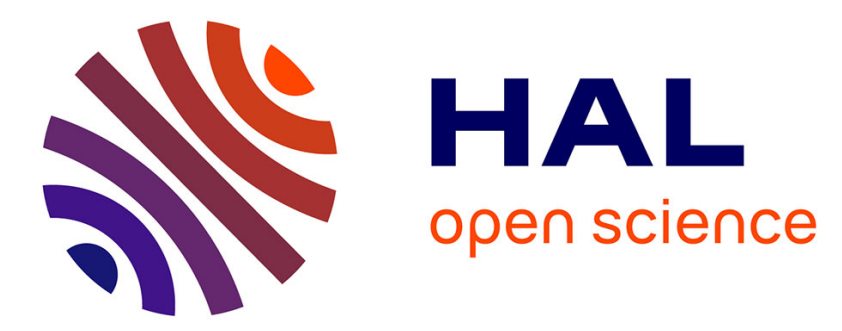

\title{
Seismic characterization of a clay-block rupture in Harmalière landslide, French Western Alps
}

Sylvain Fiolleau, Denis Jongmans, Grégory Bièvre, Guillaume Chambon, Laurent Baillet, B Vial

\section{- To cite this version:}

Sylvain Fiolleau, Denis Jongmans, Grégory Bièvre, Guillaume Chambon, Laurent Baillet, et al.. Seismic characterization of a clay-block rupture in Harmalière landslide, French Western Alps. Geophysical Journal International, 2020, 221 (3), pp.1777-1788. 10.1093/gji/ggaa050 . hal-03128222

\section{HAL Id: hal-03128222 \\ https://hal.science/hal-03128222}

Submitted on 23 Aug 2021

HAL is a multi-disciplinary open access archive for the deposit and dissemination of scientific research documents, whether they are published or not. The documents may come from teaching and research institutions in France or abroad, or from public or private research centers.
L'archive ouverte pluridisciplinaire HAL, est destinée au dépôt et à la diffusion de documents scientifiques de niveau recherche, publiés ou non, émanant des établissements d'enseignement et de recherche français ou étrangers, des laboratoires publics ou privés. 


\title{
Seismic characterization of a clay-block rupture in Harmalière landslide, French Western Alps
}

\author{
S. Fiolleau, ${ }^{1,2}$ D. Jongmans, ${ }^{1}$ G. Bièvre, ${ }^{1}$ G. Chambon, ${ }^{2}$ L. Baillet ${ }^{1}$ and B. Vial ${ }^{1}$ \\ ${ }^{1}$ Univ. Grenoble Alpes, Univ. Savoie Mont Blanc, CNRS, IRD, IFSTTAR, ISTerre, 38000 Grenoble, France. E-mail: sylvain.fiolleau@univ-grenoble-alpes.fr \\ ${ }^{2}$ Univ. Grenoble Alpes, INRAE, UR ETNA, Grenoble, France
}

Accepted 2020 January 24. Received 2020 January 24; in original form 2019 June 7

\begin{abstract}
SUMMAR Y
In late June 2016, the Harmalière clayey landslide (located $30 \mathrm{~km}$ south of the city of Grenoble, French Alps) was dramatically reactivated at the headscarp after a 35-yr-long period of continuous but limited activity. The total involved volume, which moved as sliding blocks of various sizes, was estimated to be about $2 \times 10^{6} \mathrm{~m}^{3}$. Two seismometers were installed at the rear of the main headscarp in August 2016, on both sides of a developing fracture delineating a block with a volume of a few hundred cubic metres. For 4 months, they continuously recorded seismic ambient vibrations and microearthquakes until the block broke. Five seismic parameters were derived from the monitoring: the cumulative number of microearthquakes $(\mathrm{CNe})$, the seismic energy $(S E)$, the block resonance frequency $\left(f_{B}\right)$, the relative variation in Rayleigh wave velocity $(\mathrm{d} V / V)$ deduced from noise cross-correlations between the two sensors and the associated correlation coefficient $(C C)$. All parameters showed a significant precursory signal before the rupture, but at very different times, which indicates the complexity of the rupture mechanism in this clay material.
\end{abstract}

Key words: Geomechanics; Numerical modelling; Seismic interferometry; Seismic noise.

\section{INTRODUCTION}

Numerous regions of the world are exposed to landslides in clay deposits, which pose problems for land management and population safety (Panizza et al. 1996; Guzzetti 2000; Picarelli et al. 2005; Hungr et al. 2014). The dynamics of clayey landslides is complex, showing a succession of periods of dormant activity and reactivation. Reactivation phases can evolve into sudden acceleration and catastrophic slides and/or flows (Gattinoni et al. 2012; Iverson et al. 2015; Lacroix et al. 2018), which are still difficult to forecast (Van Asch et al. 2007; Brunetti et al. 2018). The mitigation of landslide hazard then strongly depends on the ability to detect rupture precursors and requires continuous monitoring of sensitive and relevant parameters. An increasing number of studies showed that seismological methods could be relevant to monitor landslides, both in soils and rocks, through processing of both endogenous rupture signals (e.g. Amitrano et al. 2005; Spillmann et al. 2007; Lacroix \& Helmstetter 2011; Lévy et al. 2011; Walter et al. 2012; Tonnellier et al. 2013) and continuous ambient noise vibrations (e.g. Lévy et al. 2010; Del Gaudio et al. 2014; Valentin et al. 2017; Burjánek et al. 2018).

Pre-failure slope deformation usually generates numerous microruptures within the landslide body, which emit seismic signals called slide-quakes (Amitrano et al. 2005), slopequakes (Provost et al. 2018) or microearthquakes (Spillmann et al. 2007; Lévy et al. 2011). Amitrano et al. (2005) monitored microearthquakes before the collapse of a $2000 \mathrm{~m}^{3}$ chalk cliff, using a sensor located $5 \mathrm{~m}$ from the rupture plane. They showed that the seismic energy increased significantly $2 \mathrm{hr}$ before the failure. Poli (2017) also highlighted an exponential growth of seismic activity during the $10 \mathrm{hr}$ preceding the large Nuugaatsiaq landslide (Greenland) that affected a volume of $35 \times 10^{6} \mathrm{~m}^{3}$. Cases of increased induced seismicity before rupture have also been largely referenced in rocks (Amitrano et al. 2005; Senfaute et al. 2009; Lévy et al. 2011; Tonnellier et al. 2013).

As an alternative, recording ambient vibrations offers the opportunity to continuously monitor the evolution of spectral parameters (mainly resonance frequencies) and rigidity variations of the medium (seismic velocity changes) between sensors. In rocks, unstable slopes affected by open fractures usually exhibit ground motion amplification effects at discrete frequencies in specific directions. These resonance phenomena have been used to determine natural frequencies of rock blocks, columns or arches from spectral peaks contained in ambient noise measurement (Lévy et al. 2010; Bottelin et al. 2013b; Starr et al. 2015; Burjánek et al. 2018), and to follow their evolution over time. On a prone-to-fall limestone column Lévy et al. (2010) detected a significant decrease (up to 30 per cent) in resonance frequency of the fundamental mode $f_{0}$ a few weeks before the collapse. More generally, numerous studies showed that the resonance frequency of geological structures is a relevant parameter to monitor a prone-to-fall structure. To continually track this frequency, Bottelin et al. (2013b), Starr et al. (2015), Bottelin et al. (2017) and Burjánek et al. (2018) simply moni- 
tored the spectral time-series, while Bonnefoy-Claudet et al.(2006), Haghshenas et al. (2008) and Albarello \& Lunedei (2010) used the horizontal to vertical ratio $(\mathrm{H} / \mathrm{V})$, that is the spectral ratio between the horizontal and vertical components of ambient noise (Nakamura 1989). It has been shown, both numerically and experimentally that for 1-D cases the peak frequency of this ratio $f_{h / v}$ is directly related to the resonance frequency $f_{0}$. Valentin et al. (2017) used the $\mathrm{H} / \mathrm{H}$ spectral ratio (spectral ratio of the ambient noise between horizontal components of two sensors mounted close to each other) to monitor resonance frequency fluctuations of a prone-to-fall rock column. Indeed, this method allows extracting $f_{0}$ for a single object while suppressing site perturbation. In most cases, the $\mathrm{H} / \mathrm{V}$ and $\mathrm{H} / \mathrm{H}$ spectral ratios are computed in the direction of freedom of the object.

In clayey landslides, the $H / V$ method has been applied for detecting seismic impedance contrasts, using the resonance of a soft layer over a rigid medium (Jongmans et al. 2009). Méric et al. (2007) measured $H / V$ curves over two landslides and identified two peaks corresponding to the contact between the stable and unstable material and to the interface with the deeper bedrock. In contrast, Bièvre et al. (2011) conducted $H / V$ measurements over an area of several square kilometres covered with a thick layer of clay $(200 \mathrm{~m})$ overlying bedrock and affected by two adjacent 40-m-deep landslides. They identified strong $H / V$ peaks corresponding to the resonance of the clay layer, but without highlighting the interface with the landslide. In complex geometry (3-D structures), the $H / V$ ratio may also have an azimuthal variation, resulting from resonance anisotropy (Méric et al. 2007; Del Gaudio et al. 2014). In the context of landslides, where large variations in the mechanical properties of the medium over a bedrock can occur, the interpretation of $H / V$ peaks can therefore be ambiguous and must be carefully calibrated. In such case, monitoring relative changes in Rayleigh (surface) wave velocity $(\mathrm{d} V / V)$ can offer an alternative solution to study rigidity variations through ambient vibrations. The $\mathrm{d} V / V$ and the correlation coefficient $C C$ can be extracted from ambient noise using crosscorrelation (Lobkis \& Weaver 2003; Sens-Schönfelder \& Wegler 2006) and both parameters can be used to monitor changes in the medium. Larose et al. (2015a) showed that decorrelation (1-CC) can be interpreted as structural or geometric changes in the material while $\mathrm{d} V / V$ is directly related to changes in stiffness (measured by the shear wave velocity, $V s$ ) or density. Mainsant et al. (2012) continuously monitored $\mathrm{d} V / V$ on Pont Bourquin landslide and showed a 6 per cent drop in $\mathrm{d} V / V$ in the $7 \mathrm{~d}$ preceding a small mudslide.

In above-mentioned studies, reversible and seasonal variations were also observed in the spectral time-series (Lévy et al. 2011; Bottelin et al. 2013a, 2017; Starr et al. 2015; Burjánek et al. 2018; Colombero et al. 2018). These observations suggest that environmental factors influence the mechanical properties (density, rigidity) of such unstable masses. Burjánek et al. (2018) highlighted that resonance frequency variations can be either correlated with temperature fluctuations during 'warm' periods (Lévy et al. 2011; Bottelin et al. 2013a made similar observations), or anticorrelated during freezing periods. Colombero et al. (2018) showed that daily and seasonal air temperature fluctuations control resonance frequency values, spectral energy and directivity and induce reversible velocity changes within a fractured rock mass. Snieder et al. (2002) and Larose et al. (2006) showed anticorrelated changes of the velocity ratio $\mathrm{d} V / V$ with temperature for concrete and granite materials, respectively. Sens-Schönfelder \& Wegler (2006) applied the cross-correlation method on the Merapi volcano and showed that hydrological conditions can induce changes in seismic velocities by more than 10 per cent. Larose et al. (2015a) and Bièvre et al. (2018) highlighted that environmental variations (temperature, rain, etc.) induced $\mathrm{d} V / V$ fluctuations in clay materials (Pont Bourquin landslide). Finally, the cross-correlation technique was also applied on the Utiku fine-grained, slow-moving $\left(1 \mathrm{~m} \mathrm{yr}^{-1}\right)$ landslide in New Zealand (Voisin et al. 2016). Using a 400-d-long monitoring period, these authors showed a strong similarity between $\mathrm{d} V / V$ (in the range 5-10 Hz) and water table time-series. At a depth corresponding to the frequency range, the change of the water table level induced variations in both density and rigidity and, correlatively, in $V s$. Fluctuations in environmental parameters can therefore cause variations in seismic parameters, making it more difficult to track irreversible changes before failure.

The objective of this paper is to evaluate the relevance of five seismic parameters (resonance frequencies, relative changes in Rayleigh wave velocity $\mathrm{d} V / V$, correlation coefficient $C C$, cumulative number of seismic events and seismic energy) as predictors before the slip of a block that occurred at the head of a major landslide (Harmalière slide in the French Alps). This landslide was reactivated in June 2016 (Lacroix et al. 2018), and a clay block delineated by a developing rear fracture was instrumented 1 month later. Seismic and environmental parameters were monitored during a 4-month period until the collapse of the block. All five seismic parameters were calculated from the records and their variations until time to rupture were analysed. The study site and the methods are described in Sections 2 and 3, respectively, while the results are presented in Section 4. Result interpretation is supported by a 2-D finite element (FE) numerical model of the block (Section 5). Section 6 provides final discussions and conclusions.

\section{THE STUDY SITE}

Harmalière landslide is located $30 \mathrm{~km}$ south of the city of Grenoble, France (Fig. 1a), in the Trièves area affected by numerous landslides developing in a thick clayey lacustrine layer. During the last Quaternary glaciation (Würm), the Isère and Romanche glaciers moving in a southward direction dammed the rivers flowing from South, creating a lake that lasted for several thousand years (Monjuvent 1973). The landslide is located at the tongue of the former glacier. The glaciolacustrine deposits consist of a succession of layers of laminated clay and disturbed clay incorporating pebbles, resulting from the advance and retreat phases of the glacier. The total thickness of the clay varies between 0 and $250 \mathrm{~m}$, and overlies a Jurassic carbonate bedrock (Antoine et al. 1981). A thin layer of moraine caps the glaciolacustrine sequence. After glacier melting (around 14000 yr BP, Brocard et al. 2003), the rivers cut deeply into the geological formations, generating numerous landslides. The $1450-$ $\mathrm{m}$-long Harmalière landslide affects an area of around $1.8 \times 10^{6} \mathrm{~m}^{2}$, with an estimated volume of $25 \times 10^{6} \mathrm{~m}^{3}$ and a mean slope of $9^{\circ}$ (Carrière et al. 2018a). According to the classification proposed by Hungr et al. (2014), Harmalière landslide is a compound earthslide in its upper part, exhibiting numerous scarps and fracturing and an earthflow with smooth morphology in its lower part.

The landslide headscarp consists of laminated clays with multimetre interbedded layers of disturbed clays including pebbles. This clay material containing about 10 per cent smectite (Carrière et al. 2018b) shows a propensity for swelling and shrinkage. The water table is shallow and located between 2 and $5 \mathrm{~m}$, depending on the season. The gravimetric water content at shallow depth (up to $10 \mathrm{~m}$ ) ranges between 30 and 35 per cent (Bièvre et al., 2012) and can be close to the average liquid limit of about 39 per cent (Carrière et al. 2018b). In March 1981, this site suffered a first major activation 

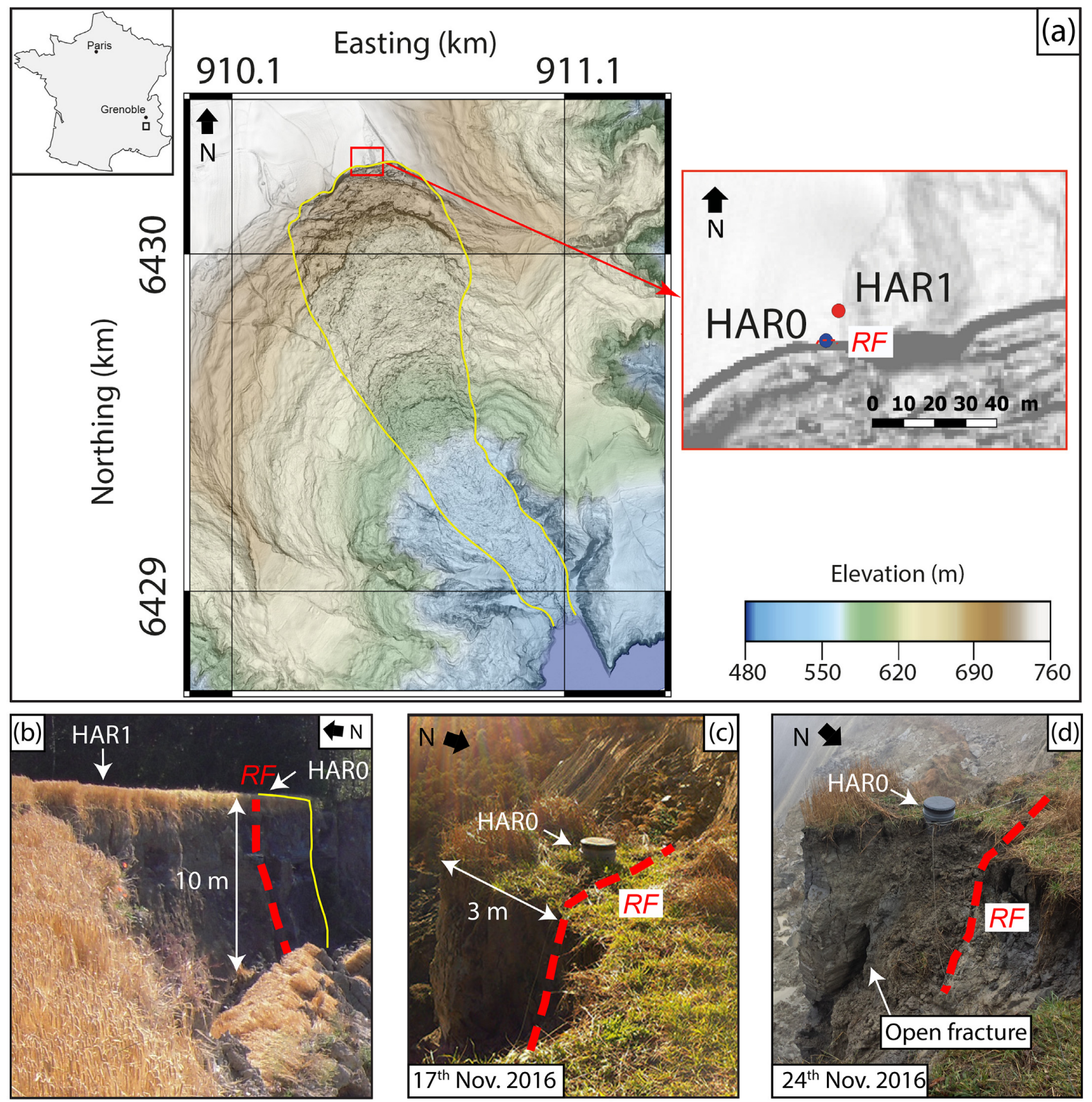

Figure 1. (a) Location of Harmalière landslide and of the study zone at the headscarp (red rectangle). The topographical map with a colour scale is derived from a LiDAR DEM acquired in 2016. A zoom of the study zone displays the position of the two three-component sensors HAR0 and HAR1. (b) West looking photograph of the headscarp and the slid block. The block position before sliding and the rear fracture are shown with yellow and dashed red lines, respectively. (c) and (d) East-looking photographs showing the clay block equipped with the seismic sensor HAR0, on November 17th and 24th, respectively.

phase affecting a surface of around $0.45 \times 10^{5} \mathrm{~m}^{2}$ after snowmelt and heavy rainfall. This landslide subsequently underwent several reactivation phases, the most significant of which took place in January 1988, January 1996, April 2001 and September 2004 (Moulin \& Robert 2004; Bièvre et al. 2011; Lacroix et al. 2018). The last major rupture at the headscarp occurred on 27 June 2016, when blocks with a total volume of about $2 \times 10^{6} \mathrm{~m}^{3}$ slid along a slip plane, generating a cliff whose height varies between a few metres and $30 \mathrm{~m}$ (Lacroix et al. 2018). This major event was followed by numerous small-scale block slides of a few tens to a few hundred of $\mathrm{m}^{3}$ all along the headscarp.

A small block was instrumented in August 2016 with two seismic sensors until its failure occurred 5 months after the main event. At the time of installation, the block was bounded by a rear fracture $3 \mathrm{~m}$ from the headscarp. During the dry period, this fracture was open (about $0.1 \mathrm{~m}$ width) to an unknown depth, while it closed during rainy periods due to shrinking and swelling of the clay. The 4-month shearing activity along this fracture surface finally isolated a small clay block (8-10 m high, $3 \mathrm{~m}$ wide and $3 \mathrm{~m}$ thick for a volume of about $70 \mathrm{~m}^{3}$, Fig. 1), which collapsed on 25 November 2016 at 7:58 GMT. Before collapsing, the block experienced a downward movement of about $0.1 \mathrm{~m}$, highlighting the effect of microsliding prior to final block rupture. This movement was accompanied by a lateral loss of material and an opening of fractures at depth (Figs 1c and d).

The geology of the block and its surroundings consists only of clay deposits. Geotechnical properties of the clays have been studied by Giraud et al. (1991), who performed triaxial tests across the 


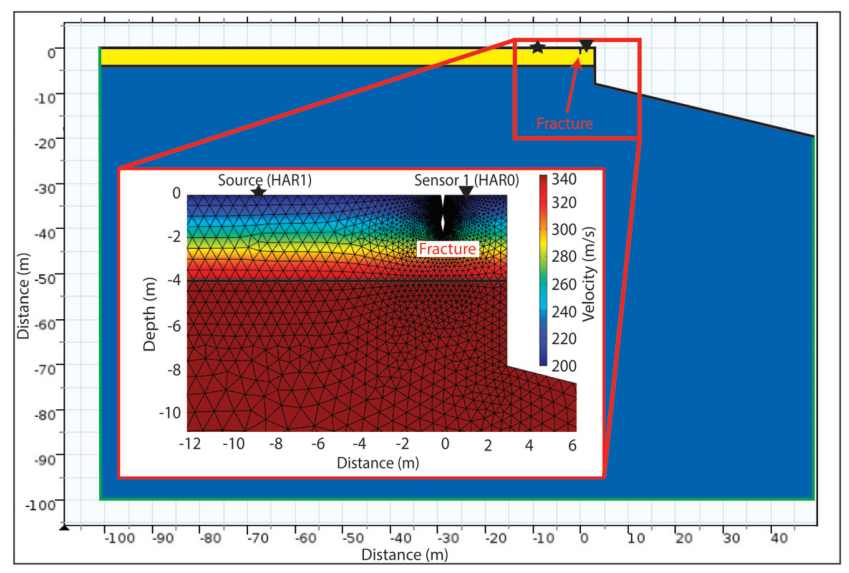

Figure 2. 2-D numerical model showing the 4-m-thick weathered clay layer (yellow) overlying the intact clay layer (blue). The positions of the source and the sensor correspond to the locations of sensors HAR 1 and HAR0, and are indicated with a star and a triangle, respectively. A zoomed-in view of the cliff zone shows the mesh refinement around the fracture and the seismic velocity $(V s)$ profile of the model. The surface is a free boundary, while the lateral and bottom limits correspond to low-reflecting boundaries. The fracture is positioned $3 \mathrm{~m}$ behind the cliff. Its depth varies from 1.8 to $6.8 \mathrm{~m}$ under the surface. A clay bridge is placed between 0.7 and $0.8 \mathrm{~m}$.

bedding and landslide back analysis for determining the peak cohesion and friction angle. Considering the average values obtained for these parameters, a simple calculation of the critical height of a vertical slope yields values of about $6 \mathrm{~m}$ (triaxial tests) and $11 \mathrm{~m}$ (back analysis). These results are consistent with the block height at the investigated site, indicating that the slope was indeed close to rupture.

\section{MATERIALS AND METHODS}

\subsection{Instrumentation}

On 25 July 2016, 2 three-component Noemax seismometers (HAR0 and HAR1) were installed $10 \mathrm{~m}$ apart at the rear of the main headscarp, on both sides of a rear fracture under development $(R F)$ which delineated the block shown in Fig. 1(c). The two sensors, characterized by an eigen period of $20 \mathrm{~s}$, were oriented northwards. They were connected to the same Kephren seismological station operated in continuous recording mode with a $200 \mathrm{~Hz}$ sampling frequency. Ambient noise was continuously recorded over a 4-month period (01 August 2016-25 November 2016) until block rupture. On two occasions after two heavy rainfalls (October 13 and November 9), the sensor on the block (HAR0) had to be refitted. These sensor displacements caused gaps in the horizontal component data, but did not affect recording of the vertical motion. The air temperature, rainfall and wind time-series were retrieved from a meteorological station belonging to the French Multidisciplinary Observatory of Versant Instabilitie (RESIF/OMIV 2006; www.ano-omiv.cnrs.fr), located $400 \mathrm{~m}$ away from the site at a similar elevation.

\subsection{Microseismicity}

Thousands of seismic events were generated before the block collapse and were extracted using a STA/LTA filter (short-time-average through long-time-average trigger; Allen 1978) with a threshold ratio of 10 and short and long windows of 5 and $100 \mathrm{~s}$, respectively.
The cumulative number of events and seismic energy recorded at both sensors were calculated daily.

\subsection{Resonance frequency analysis}

Power spectral densities (PSDs) of noise recordings for the monitored period were first computed for detecting resonance frequencies using Welch's method (Welch 1967). In order to reduce the influence of episodic energetic events and microearthquakes, data were clipped with an adaptive threshold set at four times the standard deviation of the entire detrended and demeaned signal. The polar plot of the PSD at the HAR0 sensor (on the block) was computed, showing a strong polarization along the North direction. Therefore, the spectral ratios $H_{\mathrm{N} 0} / H_{\mathrm{N} 1}$ between the northern components of HAR0 and HAR 1 were calculated over 60 -s windows for the entire period, to track the spectral evolution of the block's seismic response. An inversed (STA/LTA) filter was used to avoid the influence of energetic events in the processing, using STA and LTA windows of 100 and $300 \mathrm{~s}$, respectively, and a threshold of 2.5. For better readability, the $H_{\mathrm{N} 0} / H_{\mathrm{N} 1}$ ratio was normalized to one over the considered frequency range, and averaged over $3 \mathrm{~min}, 60 \mathrm{~min}$ or 24 $\mathrm{hr}$, depending on the analysed time period.

\subsection{Cross-correlation analysis}

The vertical components of the HAR0 and HAR1 records were cross-correlated to track potential changes in Rayleigh wave velocity, using 1-hr windows. First, the Fourier spectra of the 1-hr records were normalized for each-frequency value (spectral whitening) to ensure a similar statistical contribution of all frequencies in the considered frequency range $(1-12 \mathrm{~Hz})$. This band was defined to ensure high and stable correlation coefficient values over the first 2 months (not shown). Secondly, these 1-hr records at the two stations were cross-correlated and a reference correlogram, defined as the average of all hourly cross-correlograms over the entire period, was computed. All the correlograms were bandpass filtered for centre frequencies between 1 and $12 \mathrm{~Hz}$ over a bandwidth of $2 \mathrm{~Hz}$ and in steps of $0.5 \mathrm{~Hz}$. Then, hourly velocity changes with respect to the reference correlogram were calculated for the different frequency bands using the stretching technique (Lobkis \& Weaver 2003; Sens-Schönfelder \& Wegler 2006) in the time window [0.05$1.5 \mathrm{~s}]$ in the coda. Considering the small distance between the two sensors $(10 \mathrm{~m})$, this time window should be sufficient to account for all scattered waves in the investigated volume. The same process was used to obtain 24-hr average velocity changes from the hourly correlations for each day.

\subsection{Numerical modelling}

Two types of numerical analyses were performed to help understanding the observations: calculation of the natural frequencies of the clay block and simulation of the wave propagation to compute theoretical cross-correlograms using the finite element modelling software Comsol multiphysics (http://www.comsol.com). For both analyses, the considered 2-D model (Fig. 2) consists of two layers: a superficial 4-m-thick weathered clay layer of low mechanical properties, overlying a thicker intact clay layer. This geometry, and the corresponding seismic parameters, were determined from active seismic prospecting profiles conducted at the rear of the headscarp. In detail, the structure is made of a 4-m-thick layer of gradually weathered clay (from $V s=200$ to $340 \mathrm{~m} \mathrm{~s}^{-1} ; V p=450$ to $1000 \mathrm{~m} \mathrm{~s}^{-1}$ ) 


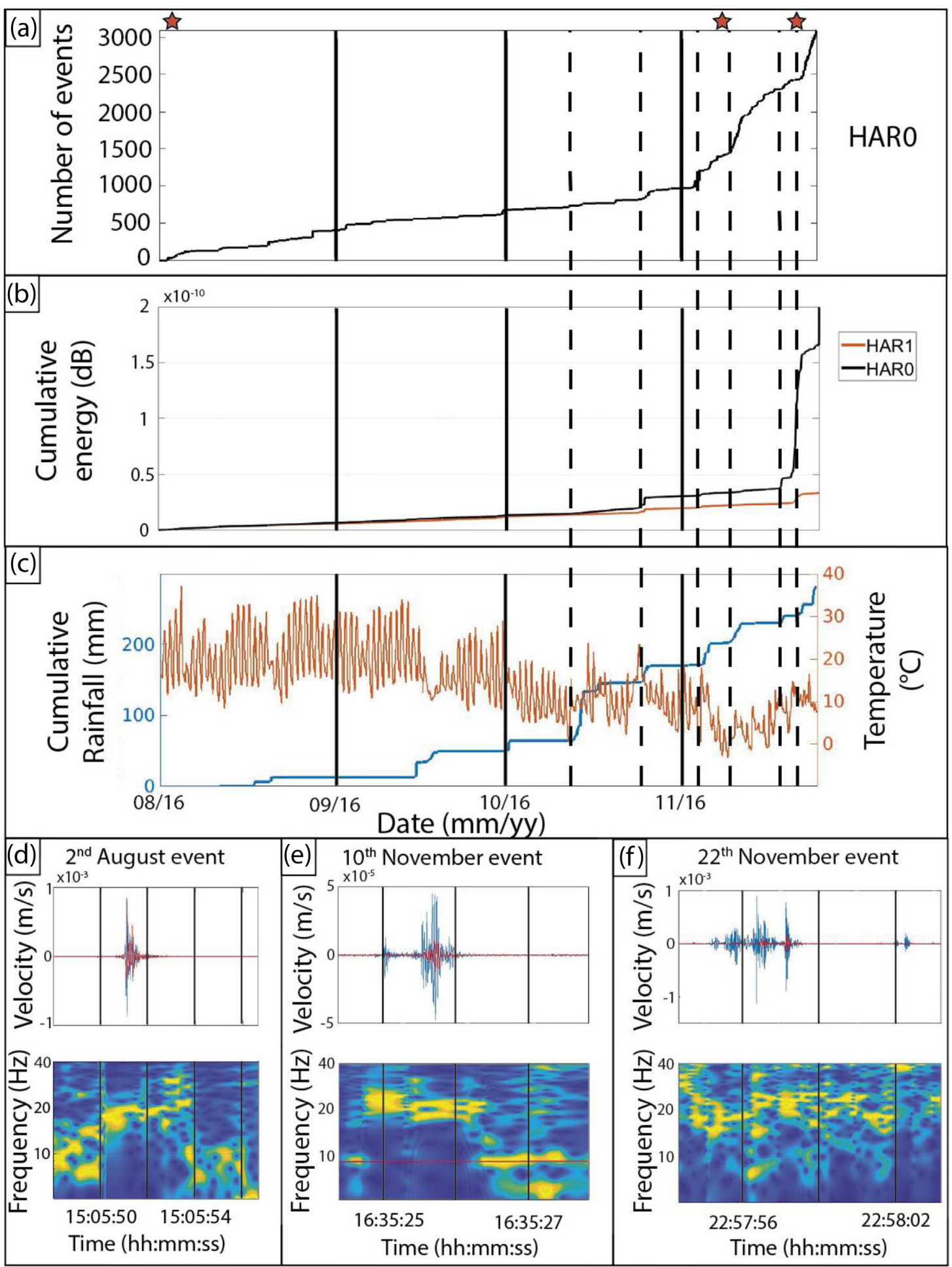

Figure 3. Microseismicity generated during the 4-month period. (a) Cumulative number of microearthquakes (CNe). (b) Cumulative seismic energy ( $S E$ ) of events for both sensors. (c) Temperature and cumulative rainfall curves. The dashed black lines underline the rain events commented on in the text. (October 13 and 25; November 4, 10, 18 and 22) (d), (e) and (f) Typical signals (blue for HAR0 and red for HAR1) and corresponding spectrograms (HAR0) recorded during the three short periods indicated by red stars in (a).

overlying laminated clays $\left(V S=340 \mathrm{~m} \mathrm{~s}^{-1} ; V p=1000 \mathrm{~m} \mathrm{~s}^{-1}\right)$. A water table of variable depth may exist in the upper more permeable layer, but it was considered dry in the modelling (taking into account the recording period in summer). An average density of $2000 \mathrm{~kg} \mathrm{~m}^{-3}$ was considered for both layers. A rear fracture located
$3 \mathrm{~m}$ from the cliff was introduced in the model, delimiting a block vibrating in bending mode. The fracture is discontinuous with a clay bridge at a depth of $0.7 \mathrm{~m}$ (Fig. 2), which was introduced to explain the evolution of the seismic parameters (see the discussion in Section 5). 
The cross-correlation simulations were performed for seven fracture depths (in the range 1.8-7.3 m). A quadratic triangular mesh was built for the whole model, with mesh refinement around the fracture in order to ensure correct wave propagation. Maximum element size $L_{\max }$ is computed according to (Mullen \& Belytschko 1982):

$L_{\max }=\frac{\lambda_{\min }}{10}=\frac{V_{\text {Rmin }}}{10 f_{\max }}$,

where $V_{R}$ is the Rayleigh wave velocity (about $0.9 V_{s}$ ) and $\lambda_{\min }$ is the minimum wavelength of the Rayleigh waves.

Considering a minimum velocity $V_{R}$ of $180 \mathrm{~m} \mathrm{~s}^{-1}$ and a maximum frequency of $40 \mathrm{~Hz}$, the smallest element was configured at $0.045 \mathrm{~m}$ in the refined zone with a maximum element growth rate of 1.3. A pseudo-Dirac source with a flat frequency response between 1 and $20 \mathrm{~Hz}$ was chosen (see Section 4.3). This source (HAR1) was positioned $9 \mathrm{~m}$ behind the fracture and the sensor 1 (HAR0) was positioned $1 \mathrm{~m}$ after the fracture (Fig. 2), similar to the field setup before the collapse of the block. A damping ratio $\xi$ was considered over the frequency band $1-12 \mathrm{~Hz}$, using the relation $Q s=V_{S} / 10$ (Olsen et al. 2003) in each medium, with $Q_{S}=2 \xi$ the quality factor. Low-reflecting boundaries were imposed at the bottom and the two lateral limits of the model.

\section{RESULTS}

\subsection{Microseismicity}

The process described in Section 3.2 identified about 3100 seismic events during the monitoring period. The cumulative number of events $C N e$ at HAR0, the cumulative seismic energy $S E$ at HAR0 and HAR1, and the cumulative rainfall and temperature evolutions are presented in Figs 3(a)-(c), respectively. CNe shows a steady increase (constant seismic activity) during the first 3 months, with a rate of about 12 events $\mathrm{d}^{-1}$. Only small and temporary increases in seismic activity $(\mathrm{CNe})$ are observed for specific precipitation events (October 1 and 25). During this period, the seismic energy is the same on both sensors, suggesting that sources are relatively remote and not located along the rear fracture delineating the block. The main rainfall on October 13-14 (69 mm) did not cause a significant increase in $\mathrm{CNe}$ and in seismic energy. In contrast, $\mathrm{CNe}$ grew dramatically on November 3, with a mean rate of about 100 events $\mathrm{d}^{-1}$ and a strong response to each subsequent precipitation. It is interesting to note that this strong growth in $\mathrm{CNe}$ occurred before a moderate rainfall on November 4-5, which then amplified the increase in seismic activity. The cumulative seismic energy at HAR0 shows a first slight increase after the rainfall of 25 October and strong rises after the last two rainfalls before rupture (18 and 22 November). After the end of October, seismic energy at HAR0 becomes higher, and much higher after end-November, than that at HAR1, suggesting that the events recorded at HAR0 are generated by local seismic sources close to the block. Three signals extracted on August 2, November 10 and 22 are plotted for the two sensors in Figs 3(d)-(f), respectively. Amplitudes at HAR0 in November are much higher than at HAR1, in agreement with the seismic energy curves.

A general analysis of the seismic events showed that most of them are impulsive, isolated (Fig. 3d) or multiple (Figs 3e and f), with some less energetic emergent events interspersed (see Figs $3 e$ and f). The impulsiveness of the events and their location close to HAR0 suggest that they are slidequakes (Provost et al. 2018), generated by the propagation of the rupture surface at the rear of the block.

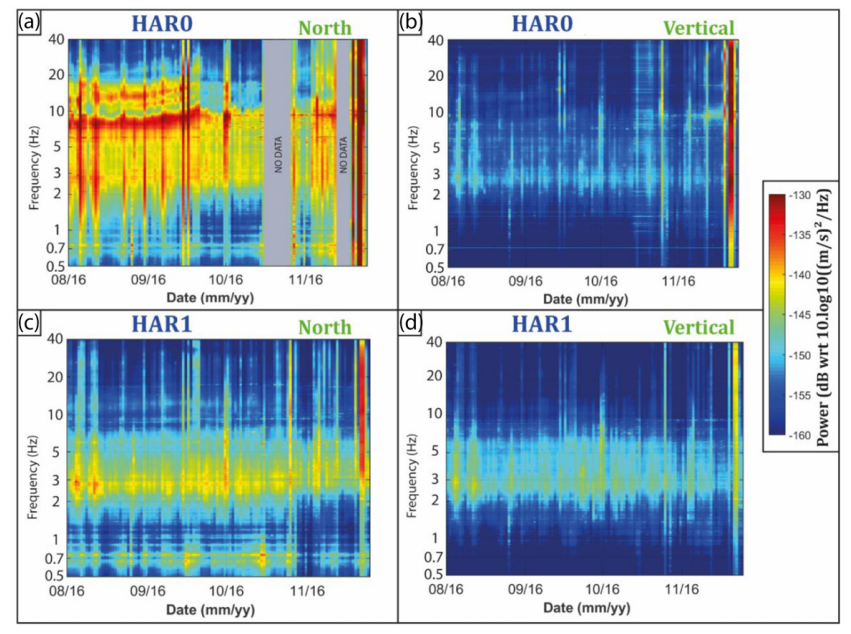

Figure 4. Power spectral density (PSD) plots computed from the ambient vibrations recorded during the 4-month period (from 25 July to 25 November 2016). (a) Sensor HAR0-North component. (b) Sensor HAR0-vertical component. (c) Sensor HAR1-North component. (d) Sensor HAR1-vertical component.

The three signals and the corresponding spectrograms shown in Fig. 3, indicate that seismic records become more complex over time. As seen on August 2 and November 10, the maximum spectral amplitude is between 7 and $12 \mathrm{~Hz}$ in seismic noise and jumps to a higher frequency band $(18-30 \mathrm{~Hz})$ during seismic events. With the increase in seismic activity in November, seismic events dominate the signals and the spectra, as shown in Fig. 3(e).

\subsection{Resonance frequency analysis}

Following Valentin et al. (2017), the resonance frequencies at the site were determined from the PSD and from the spectral ratio $H_{\mathrm{N} 0} / H_{\mathrm{N} 1}$ between HAR0 and HAR1. Fig. 4 shows the daily PSD over the 4 months at stations HAR0 and HAR1. The two gaps in the HAR0 horizontal component data result from a slight inclination of the sensor (see Section 3.1). This effect did not affect the vertical component.

The horizontal components exhibit a clear peak at a low resonance frequency $f_{1}$ around $0.7 \mathrm{~Hz}$ (Figs $4 \mathrm{a}$ and c). This frequency was previously identified as the interface between the 200-m clay deposit and the seismic bedrock (Bièvre et al. 2011). A second higher resonance frequency $f_{2}$ appears around $3 \mathrm{~Hz}$ for both horizontal and vertical components. This second frequency could correspond to a rupture surface developing at depth and decreasing the rigidity of the upper soil layer. Assuming an average shear wave velocity of $250 \mathrm{~m} / \mathrm{s}$ and applying the simple formula $h=V_{S} /\left(4 f_{2}\right)$ (Kramer 1996), the depth $h$ of this sliding surface would be at about $20 \mathrm{~m}$, an order of magnitude consistent with the height of the escarpment $(10 \mathrm{~m})$. Finally, the PSD along the northern component of sensor HAR0 (on the clay block) exhibits a strong peak at a frequency of around $9 \mathrm{~Hz}$ (Fig. 4a), which appears little on the HAR0 vertical motion, and not on the PSDs at HAR1. That frequency is interpreted as the fundamental resonance frequency of the block $f_{B}$, as confirmed by numerical simulations (see Section 5). Finally, additional peaks appear at higher frequencies (between 10 and $16 \mathrm{~Hz}$ ) on the northern component of HAR0. They could correspond to higher resonance modes of the block. From mid-September 2016, all block resonance frequencies appear to exhibit a PSD amplitude decrease (Fig. 4a). 


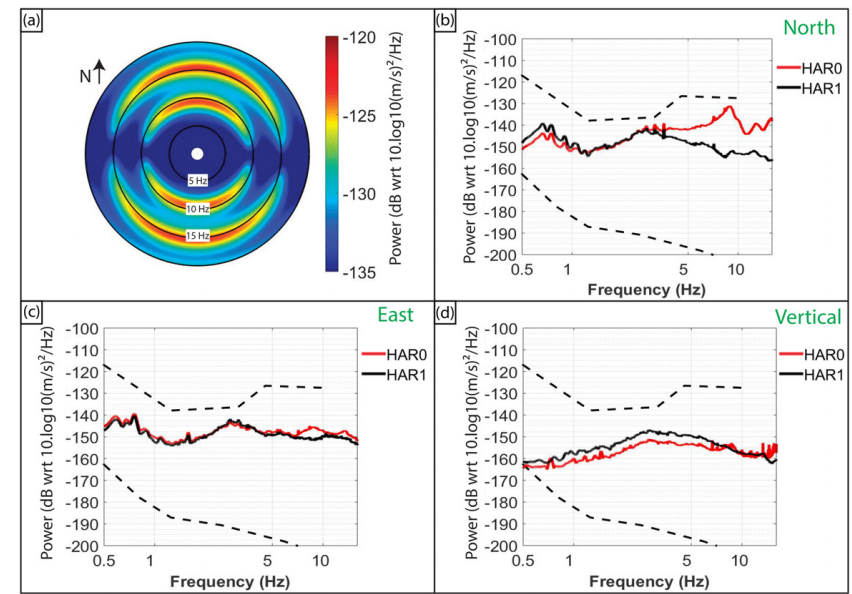

Figure 5. (a) Polar plot of the power spectral density (PSD) at the HAR0 sensor (installed on the block), computed for a 1-d recording (September 15, 2016). (b)-(d) Power spectral density computed for both sensors along the North, East and vertical component, respectively, on 15 September 2016. The dashed lines show the lower and upper seismic noise envelopes established by Peterson (1993).

Fig. 5(a) shows a polar plot of the power spectral density at the HAR0 sensor during a day without seismic activity, and indicates a vibration polarization in the North direction (bending mode) at both the fundamental block frequency around $9 \mathrm{~Hz}$ and the first mode around 15-16 Hz. Figs 5(b)-(d) show the power spectral density calculated on the North, East and vertical components of the two sensors, respectively, for the same day. All PSDs curves are within the seismic noise upper- and lower-bound envelopes proposed by Peterson (1993). While the PSDs on the two sensors are almost identical along the vertical and EW components, the PSD along the $N$ component is higher at HAR 0 above $3 \mathrm{~Hz}$, presumably due to the preferential vibration of the block.

Fig. 6(a) shows the evolution of the $H_{\mathrm{N} 0} / H_{\mathrm{N} 1}$ ratio between the two stations, averaged per day over the entire period. The only strong peak appears at the resonance frequency of the block $f_{B}$, around $9 \mathrm{~Hz}$, as also shown by the average ratio over the period (Fig. 6b). Zooming into the frequency range around $f_{B}$ (Fig. 7a), a steady increase in $f_{B}$ is observed over the 4-month period (from 8 to $9 \mathrm{~Hz}$ ), before an irregular decrease prior to rupture. In particular, $f_{B}$ increased again to $9 \mathrm{~Hz}$ on the day before the rupture. Applying a median filter (black curve in Fig. 7a), the drop appears to occur a few days before the rupture. The hourly tracking of $f_{B}$ (Fig. 7b) shows daily variations until the beginning of November when the curve becomes erratic. After this date, the increase in the number of seismic events strongly affects the determination of $f_{B}$ (as shown in Fig. 3f) and prevents its monitoring on an hourly or daily basis. An attempt was made to study the evolution of $f_{B}$ over the last $8 \mathrm{hr}$ before the rupture, by averaging the spectral ratio windows over 3 min (Fig. 7c). A pronounced decrease from 9 to $7 \mathrm{~Hz}$ is observed in the last hour before the rupture, even if the initial value is probably strongly influenced by the seismic events.

We extracted the $f_{B}$ values over one-hour periods and compared them to the temperature $T$ and cumulative rainfall time-series in Fig. 7(b). A striking feature is that the $f_{B}$ and $T$ curves exhibit opposite trends, suggesting that the rise in $f_{B}$ from 8 to $9 \mathrm{~Hz}$ over the 4 months of the study could be related to the average decrease in $T$ from 25 to $0^{\circ} \mathrm{C}$. The $f_{B}$ curve also shows daily variations that appear to be anticorrelated with $T$ fluctuations, with a 6-7 hr lag (Fig. 7d). Also of particular interest are the reversible increases
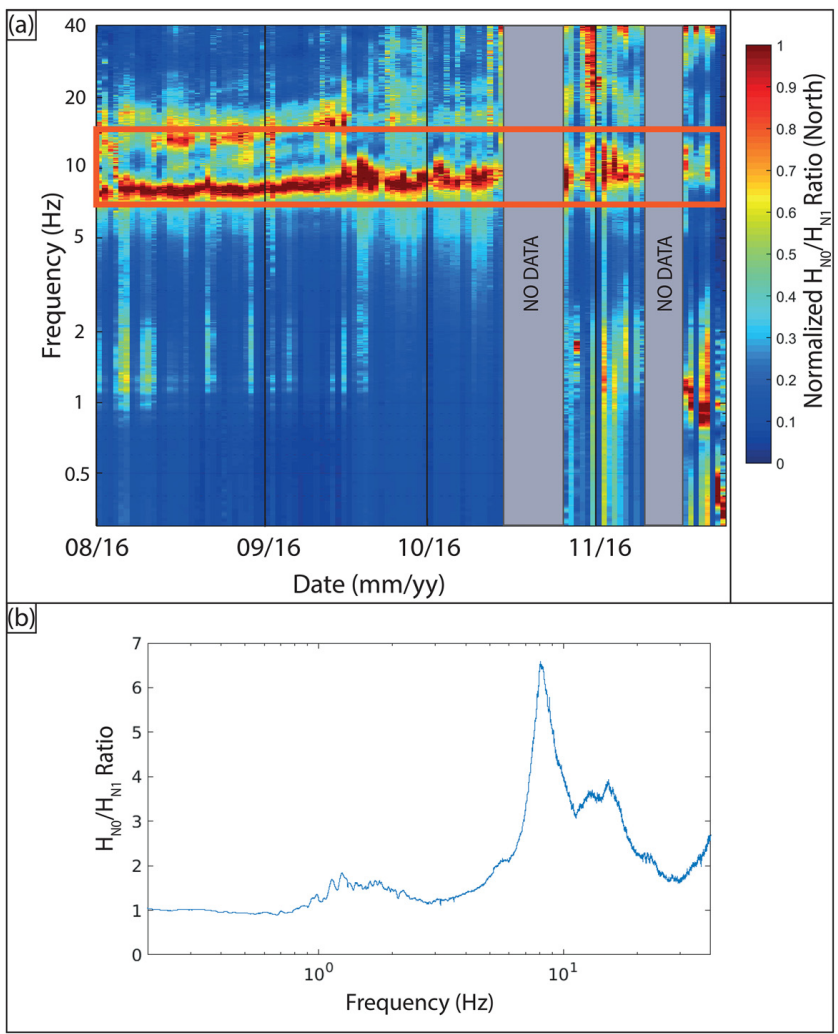

Figure 6. (a) Daily normalized $H_{\mathrm{N} 0} / H_{\mathrm{N} 1}$ ratio between HAR0 and HAR 1 along the North component during the 4-month period. (b) Non-normalized $H_{\mathrm{N} 0} / H_{\mathrm{N} 1}$ ratio averaged over the whole period.

in $f_{B}$, which are subsequent to rainfalls (see stars in Fig. 7b) and last for several days. This observation will be discussed further in Section 6.

\subsection{Cross-correlations}

As explained in Section 3.4, the records at stations HAR0 and HAR1 were hourly cross-correlated in the frequency range $1-12 \mathrm{~Hz}$ and then daily averaged. The cross-correlograms over the entire period show that the slight tilting and refitting of sensor HAR0 (see Section 3.1) had no influence on the correlation results computed from the vertical components. Fig. 8 shows the changes in Rayleigh wave propagation velocity $(\mathrm{d} V / V$, Fig. $8 \mathrm{a})$, in correlation coefficient $(C C$, Fig. 8 b) and in environmental parameters (temperature and rainfall, Fig. 8c) over the 4 months of the monitoring period. Before October 13, $\mathrm{d} V / V$ and $C C$ show little changes, with the exception of a few limited occasional variations at high frequencies above $9 \mathrm{~Hz}$. Values of $\mathrm{d} V / V$ and $C C$ remain globally around 0 and 1 , respectively, which suggests no significant change in the medium. In contrast, from October 13, drops in $C C$ and variations in $\mathrm{d} V / V$ (reaching \pm 10 per cent) develop first at high frequencies, and then gradually extend to the low frequency range. This evolution is particularly visible on $C C$, which shows values lower than 0.4 over the entire frequency range just before the rupture. The start of the $C C$ degradation coincides with the main rain event of October 13-14 (about $70 \mathrm{~mm}$ in $2 \mathrm{~d}$; Fig. 8c). After that date, each precipitation generates a further drop in $C C$ (and variations in $\mathrm{d} V / V$ ) over an increasingly frequency range towards low frequencies (see the dashed line in Figs $8 \mathrm{a}$ and b). Between two successive rain events, the $C C$ values may temporally 


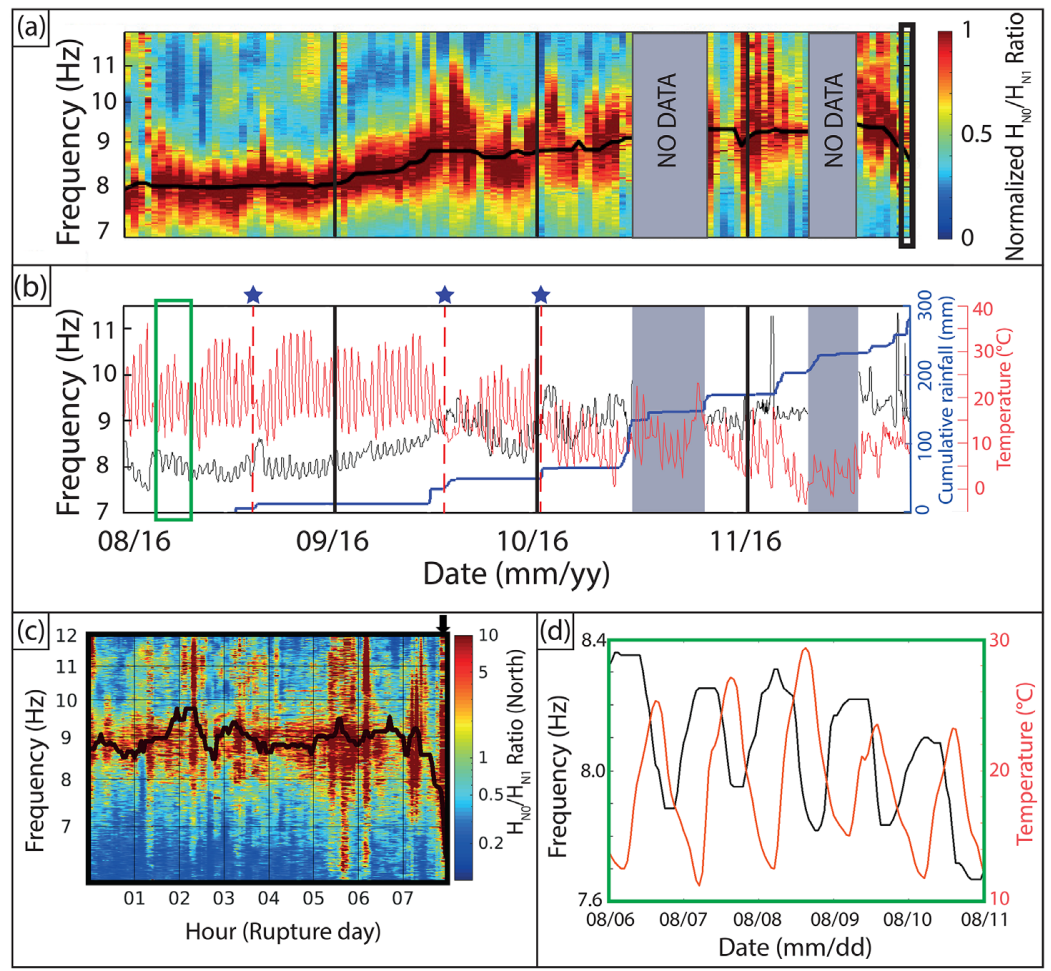

Figure 7. Detailed $H_{\mathrm{N} 0} / H_{\mathrm{N} 1}$ ratio analysis. (a) Zoom in the frequency band 7-12 Hz (red rectangle in Fig. 6a). The black line represents the maximum values of the daily $H_{\mathrm{N} 0} / H_{\mathrm{N} 1}$ smoothed by a median filter $(11 \mathrm{~d})$ (b) Time-series of cumulative rainfall, temperature and resonance frequency extracted from the $H_{\mathrm{N} 0} / H_{\mathrm{N} 1}$ ratio between 7 and $12 \mathrm{~Hz}$ over the 4-month recording period. The stars and dashed red lines show the precipitation events that coincide with reversible increases in $f_{b}$. (c) Non-normalized $H_{\mathrm{N} 0} / H_{\mathrm{N} 1}$ ratio (3-min-long records-North component) during the $8 \mathrm{hr}$ preceding the rupture (black rectangle in Fig. 7a) (25 November 2016). The black line represents the maximum values smoothed by a median filter ( $135 \mathrm{~min})$. The rupture time is indicated with a black arrow. (d) Enhanced view of the time-series of temperature and resonance frequency between the 6th and the 11th of August 2016 (green rectangle in Fig. 7b).

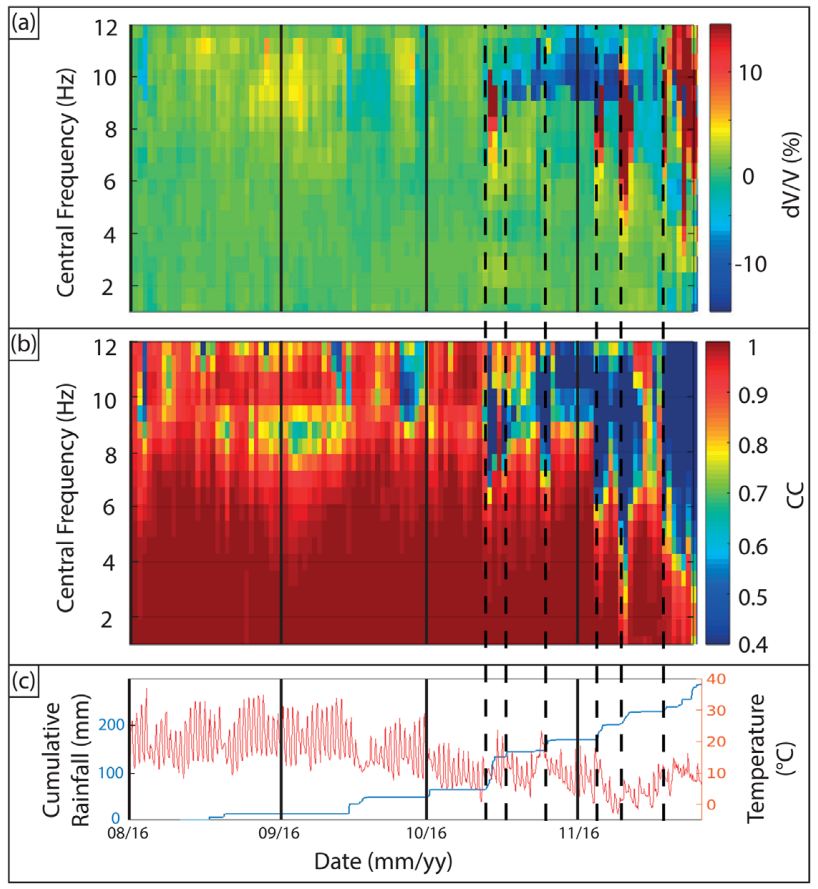

Figure 8. Daily cross-correlation analysis between sensors HAR0 and HAR1 over the 4-month period. (a) Rayleigh wave velocity variation $(d V / V)$ between 1 and $12 \mathrm{~Hz}$. (b) Correlation coefficient (CC). (c) Cumulative rainfall in mm (blue curve) and air temperature in ${ }^{\circ} \mathrm{C}$ (red curve). The dashed black lines highlight the main rain events.

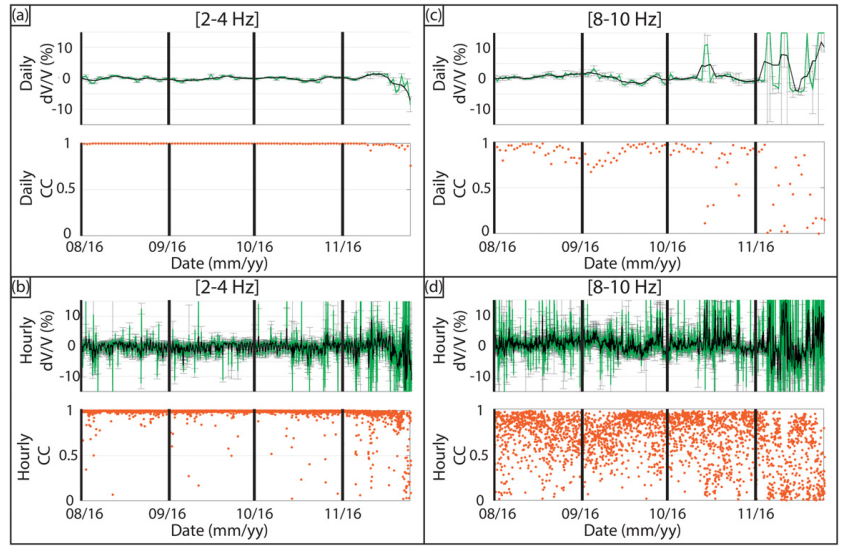

Figure 9. Cross-correlation analysis between sensors HAR0 and HAR 1 over the 4-month period. In all plots, $\mathrm{d} V / V$ data (green curve) are shown with error bars and smoothed with a Savitzky-Golay filter of polynomial order 3 and frame size 5 (black curve). The corresponding correlation coefficient is shown in red. (a) Daily cross-correlations in the frequency band [2-4 Hz]. (b) Hourly cross-correlations in the frequency band [2-4 Hz]. (c) Daily crosscorrelations in the frequency band [8-10 Hz]. (d) Hourly cross-correlations in the frequency band $[8-10 \mathrm{~Hz}]$.

re-increase. After November 15, the $C C$ values drop irreversibly until the rupture (November 25).

The daily $\mathrm{d} V / V$ and $C C$ curves are shown in more detail in two frequency bands $(2-4 \mathrm{~Hz}$ and $8-10 \mathrm{~Hz}$ ) corresponding to the two main site resonance frequencies in Figs 9(a) and (c). Error bars calculated according to Weaver et al. (2011) are also represented. 
In the $2-4 \mathrm{~Hz}$ band, $\mathrm{d} V / V$ and $C C$ values remain stable until $10 \mathrm{~d}$ before rupture, when a decrease in $d V / V$ is observed, as well as a slight decrease in $C C$. In the $8-10 \mathrm{~Hz}$ range, the $\mathrm{d} V / V$ and $C C$ curves are more unstable, particularly after October 10 when $\mathrm{d} V / V$ shows temporary variations of more than 10 per cent associated with high errors, and $C C$ drops to almost 0 . This behaviour is probably due to the block resonance that disrupts the correlation in this frequency band. We then examined the hourly variations of $\mathrm{d} V / V$ and $C C$ in the same two frequency bands (Figs $9 \mathrm{~b}$ and d), in order to investigate the potential of both parameters as precursors. The results show that both parameters are much more unstable, with very strong variations, in the $8-10 \mathrm{~Hz}$ frequency range. In the last month prior to the rupture, $\mathrm{d} V / V$ error bars are large and associated with low $C C$ values $<0.6$, preventing the use of hourly parameters for robust analyses.

\section{NUMERICAL MODELLING}

One major constraint for the modelling is the weak changes in block resonance frequency $f_{B}$ over time, which exhibits a slight increase apparently correlated to temperature and dropped in the last hour before the block rupture. These observations discard the classical model of a rear fracture deepening over time, proposed in rocks by Lévy et al. (2010) to explain the decrease in resonance frequency before failure. Observations of the clay cliff (Figs 1c and d) show the presence of open fractures at surface and depth. The upper fracture, which is affected by weather conditions, exhibits significant opening variations $(0-0.2 \mathrm{~m})$ in relation with the swelling and shrinking of the clay. One explanation to the little variations in $f_{B}$ could be the presence of a clay bridge separating the upper and lower fractures. On this basis, we propose a model made of two isolated fracture zones (Fig. 2), with a triangle-shaped upper fracture with an opening of $0.2 \mathrm{~m}$ at the surface and a depth of $0.7 \mathrm{~m}$, and a diamond-shaped lower fracture with a width of $0.2 \mathrm{~m}$ and an initial height of $1 \mathrm{~m}$ (depth of the base at $1.8 \mathrm{~m}$ ). The two fractures are separated by a 0.1 -m-thick clay bridge. The depth of the clay bridge $(0.7 \mathrm{~m})$ was fixed to obtain a resonance frequency around $9 \mathrm{~Hz}$, studying the spectral modal response of the model. We then modelled the effect of the deepening of the lower fracture on the seismic response of the block, using the pseudo-Dirac source shown at the top of Fig. 10. The signals simulated at sensor 1 (HAR0) and the corresponding Fourier spectra are shown in the same figure for seven fracture depths (from 1.8 to $7.3 \mathrm{~m}$ ). With deepening of the lower fracture, a minimum appears in the Fourier spectrum at a frequency $f *$ that gradually decreases. This change in the spectrum is interpreted as a filtering effect of the fracture. In a half-space with a simple fracture, waves are low-pass filtered by the fracture (Hévin et al. 1998; Bièvre et al. 2012), at a cut-off frequency that depends on the ratio between the wave velocity and the fracture depth. Here, the effect of the lower fracture appears to be more complex and behaves as a notch filter.

The signals simulated at sensor 1 (HAR0) were cross-correlated with the seismic source for all fracture depths. The $\mathrm{d} V / V$ values were calculated from the model, using as a reference the correlation obtained for an initial depth of $1.8 \mathrm{~m}(0.7 \mathrm{~m}$ for the upper fracture, $0.1 \mathrm{~m}$ for the bridge and $1 \mathrm{~m}$ for the lower fracture). Fig. 11 compares the computed values of $\mathrm{d} V / V$ and $C C$ (Figs $11 \mathrm{~b}$ and $\mathrm{d}$, respectively) with the experimental data (Figs $11 \mathrm{a}$ and $\mathrm{c}$ ). Note that $x$-axes for experimental and numerical data correspond to time and fracture depth, respectively. The vertical dashed line shows the time and fracture depth at which a first significant decrease in $C C$ appear, both experimentally and numerically. Numerical results show that
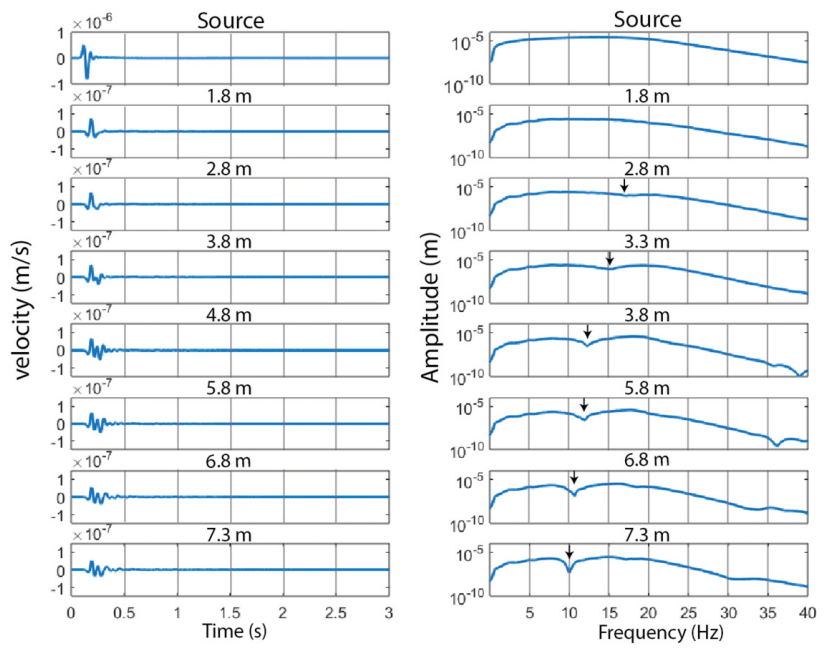

Figure 10. Synthetic signals and spectra simulated at sensor 1 (HAR0, see model in Fig. 2) for 7 values of fracture depth ranging between 1.8 and $7.3 \mathrm{~m}$. The seismic source signal and spectrum are shown at the top of the figure.

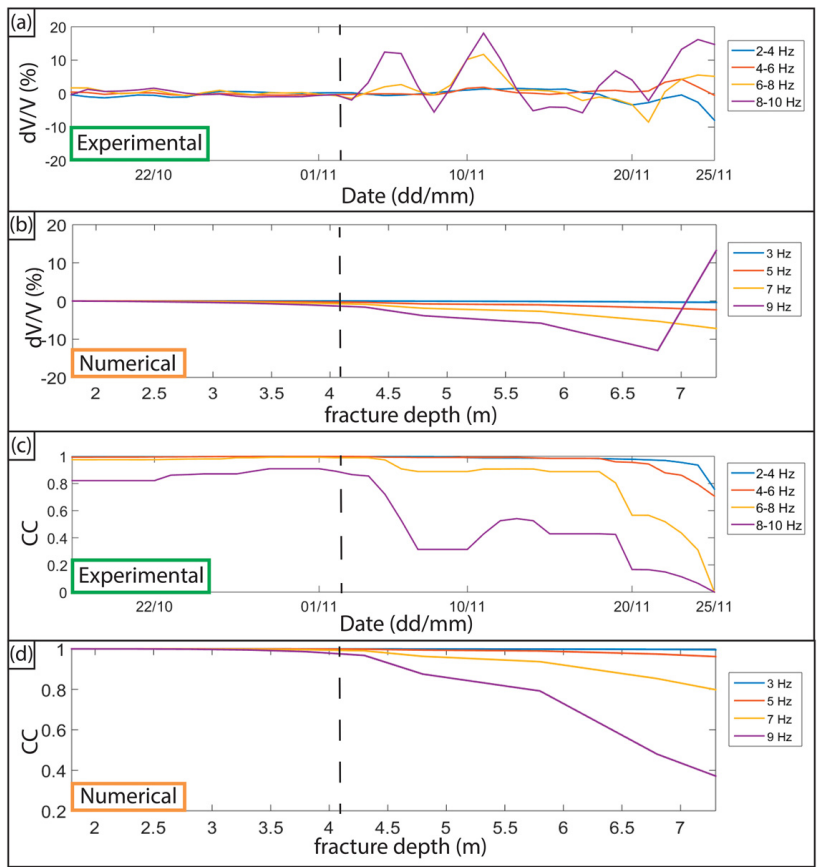

Figure 11. Effect of the fracture depth on Rayleigh wave velocity variations $(\mathrm{d} V / V)$ and correlation coefficient $(C C)$ for different frequency bands. (a) Experimental values of $\mathrm{dV} / \mathrm{V}$ over the 2 last months before the rupture for the frequency bands $2-4 \mathrm{~Hz}, 4-6 \mathrm{~Hz}, 6-8 \mathrm{~Hz}$ and $8-10 \mathrm{~Hz}$. (b) Numerical values of $\mathrm{d} V / V$ as a function of fracture depth for frequencies of $3 \mathrm{~Hz}, 5 \mathrm{~Hz}$, $7 \mathrm{~Hz}$ and $9 \mathrm{~Hz}$. (c) Experimental value of CC. (d) Numerical values of $\mathrm{CC}$. The black dashed line approximately corresponds to the first significant decrease in $\mathrm{CC}$ in both experimental and numerical data.

increasing fracture depth up to $7.3 \mathrm{~m}$ causes variations in $\mathrm{d} V / V$ (Fig. 11b) at high frequencies (above $7 \mathrm{~Hz}$ ), which can reach more than 10 per cent at $9 \mathrm{~Hz}$. These variations are of the same order of magnitude as those extracted from the experimental data (Fig. 11a). Deepening the lower fracture also causes a significant decrease in $C C$ (to values as low as 0.4 ), first affecting the high frequencies and moving towards the low frequencies. At low frequency $(3 \mathrm{~Hz})$, a fracture of $7.3 \mathrm{~m}$ has low influence on the $C C$ and $\mathrm{d} V / V$ curves. 
Overall, these numerical results are in good agreement with the experimental data, particularly concerning the shape and magnitude of the $C C$ curves. Modal analysis shows that the deepening of the lower fracture has little effect on the first resonance frequency $f_{B}(5$ per cent variations), which is mainly controlled by the clay bridge at $0.7 \mathrm{~m}$ depth.

The numerical modelling made it possible to retrieve the main observations made on the $C C, \mathrm{~d} V / V$ and $f_{B}$ parameters during the period preceding the rupture. In particular, this analysis seems to validate the interpretation of experimental observations in terms of progressive deepening of the lower fracture. It should be noted, however, that this modelling may not be unique to explain the observations, and does not simulate the dynamic mechanism of rupture, in particular the effect of rainfalls.

\section{DISCUSSION AND CONCLUSIONS}

A synthesis of recorded seismic and environmental time-series is shown in Fig. 12. Five seismic parameters were monitored during 4 months until rupture of a clay block: the resonance frequency $\left(f_{B}\right)$, the relative variation in Rayleigh wave velocity $(\mathrm{d} V / V)$ and the correlation coefficient $(C C)$ in the range $1-12 \mathrm{~Hz}$, the cumulative number of seismic events $(\mathrm{CNe})$ and the seismic energy ( $S E$, see Figs 12a-d). All these parameters appear to show a precursory signal before the rupture, but at different times. During the monitoring period, these parameters also reacted differently to environmental forcing and in particular to rainfalls. Resonance frequency $f_{B}$ increased slightly but steadily from 8 to $9 \mathrm{~Hz}(+12$ per cent) during the pre-rupture period (Fig. 12a). Rainfalls (Fig. 12e) caused temporary reversible increases in $f_{B}$, but had little impact on the overall increasing trend (Fig 12b), which appears to be mainly controlled by temperature. In addition, $f_{B}$ shows a decreasing trend a few days before the rupture (Fig. 12a), but the concomitant increase in the number of seismic events prevents accurate monitoring of this parameter during this period. In contrast, the other four parameters show significant variations a few weeks before failure. Parameters $\mathrm{d} V / V$ and $C C$ reacted first on October 13, at the time of the highest rainfall 6 weeks before failure. In general, $\mathrm{d} V / V$ values show complex, non-monotonic variations depending on the frequency (Fig 12b). After most rain events, however, a quick increase in $\mathrm{d} V / V$ is observed in the band $8-10 \mathrm{~Hz}$. Concurrently, $C C$ (Fig. 12c) exhibits a general decrease over time, affecting first the high frequencies and then gradually propagating to the low frequencies. The overall decrease in $C C$ appears to be related to successive rain events, until low $C C$ values are observed over almost the entire frequency range during the last week before rupture. Finally, microseismic activity $(\mathrm{CNe})$ and seismic energy $(S E)$ are almost constant during the first 3 months, exhibiting only slight temporary increases during precipitation events. In particular, the major rainfall of 13 October did not cause any significant increase in $\mathrm{CNe}$ or $\mathrm{SE}$. Conversely, after the relatively small rainfall of November 4, CNe experienced a rapid growth, which is not observed on the seismic energy $S E$. These results suggest that numerous weak events occurred at the vicinity of the block. After November 4, CNe showed an increased sensitivity to rainfall, while the major increase in seismic energy occurred only during and after the rainfall of November 22.

These results are complex but suggest the following sequence of events. At the beginning of the monitoring period, the block was already partially decoupled from the clay mass by a rear fracture, as attested by in situ observations and the measurement of a resonance frequency with a bending mode. The upper part of the fracture may be filled by air or soft clay, depending on weather conditions (dry

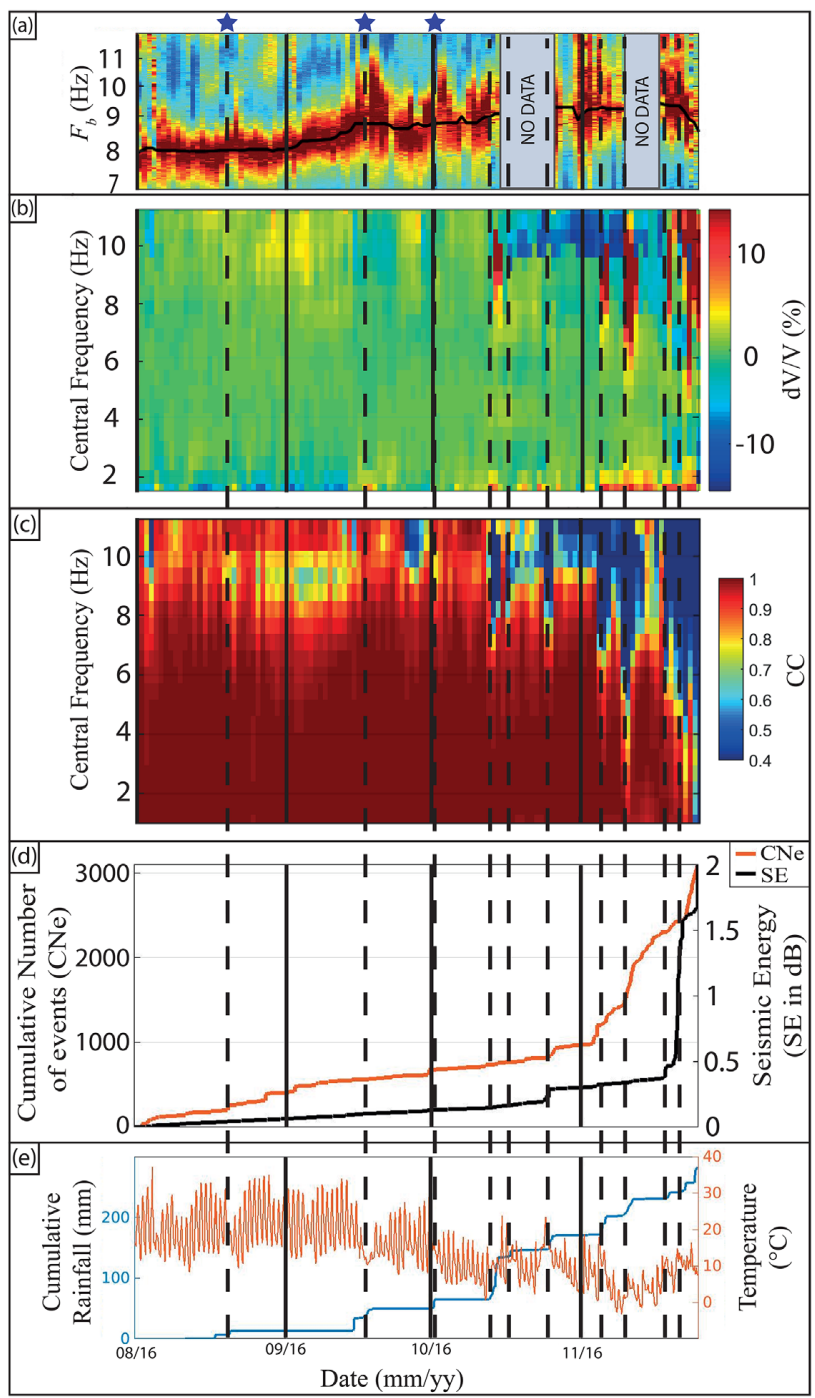

Figure 12. Summary figure showing the evolution of the five seismic parameters studied (a) Normalized $\mathrm{H}_{\mathrm{N} 0} / \mathrm{H}_{\mathrm{N} 1}$ ratio analysis zoomed in the frequency band $7-12 \mathrm{~Hz}$. The stars show the precipitation events that coincide with increases in resonance frequency $f_{B}(\mathrm{~b})$ Rayleigh wave velocity variation ( $\mathrm{d} V / V)$ between 1 and $12 \mathrm{~Hz}$. (c) Correlation coefficient $(C C)$. (d) Cumulative number of microearthquakes ( $\mathrm{CNe}$, red curve) and the cumulative seismic energy ( $S E$, black curve). (e) Temperature and cumulative rainfall. The dashed black lines highlight the main rain events.

or wet). Since the resonance frequency $f_{B}$ did not decrease during the monitoring period, we assume that the block remains attached to the stable cliff by a clay bridge. A model with two fractures separated by this clay bridge has been proposed. Until October 13, the steady seismic activity indicated a continuous mechanical degradation along the headscarp, generating microruptures. The block remained stable and no significant variations in $d V / V$ and $C C$, or decrease in $f_{B}$, were recorded, suggesting little or no variations in the medium between sensors and in the block characteristics (internal rigidity, fracture depth, contact rigidity). After the $70 \mathrm{~mm}$ rainfall of October 13-14, the upper medium between stations changed, as evidenced by the $\mathrm{d} V / V$ fluctuations and the $C C$ decrease for the highest frequencies considered in the study (around $10 \mathrm{~Hz}$ ). This medium change also affected the $H_{\mathrm{N} o} / H_{\mathrm{N} I}$ ratio amplitude, suggesting that it occurred in the block or at the contact between the block and the rear clayey mass. In contrast, the seismic activity remained steady, indicating that the block was still stable. 
On October 25 , the seismic activity increased after high precipitations $(22 \mathrm{~mm})$ that also caused low variations in $\mathrm{d} V / V$ and a significant drop in $C C(<0.5)$. This time is interpreted as the start of the block sliding process. After this date, each subsequent rainfall induced amplified variations of $C N e, \mathrm{~d} V / V$ and $C C$ until rupture, but seismic energy $(S E)$ did not increase significantly until after November 22. This increase of the seismic energy could result from the sliding of the neighbouring blocks and/or the deepening of the lower fracture at depth, as suggested in the November 24 photo (Fig. 2d). The general trend of $f_{B}$ does not seem to be affected by these processes, but it should be noted that rainfalls generally coincide with increases in $f_{B}$ with a much larger amplitude than those observed in the preceding period. However, the high number of seismic events may also influence the determination of $f_{B}$ values, due to the shift of spectral energy to a higher frequency during events (Fig. 3c). On November 25, the drop in $f_{B}$ (Fig. 12a) indicates a major change at the interface between the block and the soil mass that occurred one hour before collapse. It can be interpreted as the onset of final block destabilization.

Of particular interest are the strong $f_{B}$ variations with rainfalls observed during the monitoring period. For three rainfalls (20/08/2016, $17 / 09 / 2016$ and $01 / 10 / 2016), f_{B}$ increases over a period of about $2-3$ d. At first sight, such observations are unexpected, since an increase in water content should result in an increase of density and a decrease of shear modulus, both yielding a reduction of $f_{B}$ and $V_{S}$ (Voisin et al. 2016). As explained above (Section 4.2), $f_{B}$ is anticorrelated to temperature and rainfalls that lowers temperature can cause increases in $f_{B}$. However, it is unlikely that such strong variations are generated solely by thermal effects. One possible explanation is that rainfalls temporarily change the contact between the block and the mass, that is that the fracture could close and re-open with the precipitation-induced swelling and shrinking of the clay in the upper medium. On November 6, a sharp increase in $f_{B}$ was concomitent to an increase in seismic activity. A detailed analysis of the data points out that the microseismicity initiation and the $f_{B}$ increase precedes the day's rainfall, highlighting the effect of seismic events on $f_{B}$ (Figs $3 a$ and $b$ ). Finally, seismic energy increased considerably a few days before the block slipped and appears to be a robust precursor to the rupture.

In conclusion, this study has shown the value of seismic monitoring for tracking ruptures in clayey landslides. Unlike unstable rock columns (Lévy et al. 2010), no precursory decrease in natural frequency was observable over the few weeks preceding rupture, probably due to the presence of a shallow clay bridge. In contrast the seismic activity and energy, the Rayleigh wave velocity variations $\mathrm{d} V / V$ and the correlation coefficient $C C$ showed precursory patterns that could be exploited. In particular, the progressive decrease in $C C$ from high to low frequency is remarkable. However, as highlighted by different authors (Hilloulin et al. 2014; Larose et al. 2015b), the correlation coefficient can be influenced by various factors, and its robustness for monitoring purposes needs to be further investigated. Reversible variations in seismic parameters $\left(f_{B}, \mathrm{~d} V / V\right.$ and $\left.C C\right)$ appear to be complex and are not fully understood at this stage, like the increase in $f_{B}$ with temperature. An interpretation of these effects and the understanding of the rupture mechanism would require the measurement of hydraulic data at different depths and specific laboratory tests investigating the thermomechanical behavior of the clay.

\section{ACKNOWLEDGEMENTS}

This work benefited from financial support from the VOR program (Université Grenoble Alpes), the French national program C2ROP, and the French National Research Agency in the framework of the Investissements d'Avenir program (ANR-15-IDEX-02, CDPRISK). This work was partly supported by the project SIMOTER 1 funded by the European Union under the ERDF-POIA program and by the French government under the FNADT - CIMA program. Meteorological data were provided by OMIV (Multidisciplinary Observatory of Versant Instabilities; (RESIF/OMIV 2006; www. ano-omiv.cnrs.fr)). The authors are part of LabEx OSUG@2020 (ANR10 LABX56). The authors thank three anonymous reviewers and the editor who greatly helped to enhance the quality of this paper.

\section{REFERENCES}

Albarello, D. \& Lunedei, E., 2010. Alternative interpretations of horizontal to vertical spectral ratios of ambient vibrations: new insights from theoretical modeling, Bull. Earthq. Eng., 8, 519-534.

Allen, R.V., 1978. Automatic earthquake recognition and timing from single traces, Bull. seism. Soc. Am., 68, 1521-1532.

Amitrano, D., Grasso, J.R. \& Senfaute, G., 2005. Seismic precursory patterns before a cliff collapse and critical-point phenomena, Geophys. Res. Lett., 32, L08314, doi:10.1029/2004GL022270.

Antoine, P., Giraud, A. \& Montjuvent, G., 1981. Les argiles litées du Trièves (Isère) ; conditions de gisement et exemples de propriétés géotechniques, Bull. Soc. géol. Fr., 7(XXIII), 117-127.

Bièvre, G., Jongmans, D., Winiarski, T. \& Zumbo, V., 2012. Application of geophysical measurements for assessing the role of fissures in water infiltration within a clay landslide (Trièves area, French Alps), Hydrol. Process., 26, 2128-2142.

Bièvre, G., Knieß, U., Jongmans, D., Pathier, E., Schwartz, S., van Westen, C.J., Villemin, T. \& Zumbof, V., 2011. Paleotopographic control of landslides in lacustrine deposits (Trièves plateau, French western Alps), Geomorphology, 125, 214-224.

Bièvre, G., Franz, M., Larose, E., Carrière, S., Jongmans, D. \& Jaboyedoff, M., 2018. Influence of environmental parameters on the seismic velocity changes in a clayey mudflow (Pont-Bourquin Landslide, Switzerland), Eng. Geol., 245, 248-257.

Bonnefoy-Claudet, S., Cotton, F. \& Bard, P.-Y., 2006. The nature of noise wavefield and its applications for site effects studies: a literature review, Earth-Sci. Rev., 79, 205-227.

Bottelin, P., Baillet, L., Larose, E., Jongmans, D., Hantz, D., Brenguier, O., Cadet, H. \& Helmstetter, A., 2017. Monitoring rock reinforcement works with ambient vibrations: La Bourne case study (Vercors, France), Eng. Geol., 226, 136-145.

Bottelin, P., Jongmans, D., Baillet, L., Lebourg, T., Hantz, D., Lévy, C., Le Roux, O. et al., 2013a. Spectral analysis of prone-to-fall rock compartments using ambient vibrations, J. Environ. Eng. Geophys., 18, 205.

Bottelin, P., Lévy, C., Baillet, L., Jongmans, D. \& Guéguen, P., 2013b. Modal and thermal analysis of Les Arches unstable rock column (Vercors massif, French Alps), Geophys. J. Int., 194, 849-858.

Brocard, G.Y., van der Beek, P.A., Bourlès, D.L., Siame, L.L. \& Mugnier, J.L., 2003. Long-term fluvial incision rates and postglacial river relaxation time in the French Western Alps from 10Be dating of alluvial terraces with assessment of inheritance, soil development and wind ablation effects, Earth planet. Sci. Lett., 209, 197-214.

Brunetti, M.T., Melillo, M., Peruccacci, S., Ciabatta, L. \& Brocca, L., 2018. How far are we from the use of satellite rainfall products in landslide forecasting?, Remote Sens. Environ., 210, 65-75.

Burjánek, J., Gischig, V., Moore, J.R. \& Fäh, D., 2018. Ambient vibration characterization and monitoring of a rock slope close to collapse, Geophys. J. Int., 212, 297-310.

Carrière, S., Jongmans, D., Chambon, G., Bièvre, G., Lanson, B., Bertello, L., Berti, M. et al., 2018a. Rheological properties of clayey soils originating from flow-like landslides, Landslides, 15, 1615-1630.

Carrière, S., Bièvre, G., Jongmans, D., Chambon, G., Bellot, H. \& Lebourg, T., 2018b. Measurement of geophysical parameters on clay samples at the solid-fluid transition, Near Surf. Geophys., 16, 23-37. 
Colombero, C., Baillet, L., Comina, C., Jongmans, D., Larose, E., Valentin, J. \& Vinciguerra, S., 2018. Integration of ambient seismic noise monitoring, displacement and meteorological measurements to infer the temperaturecontrolled long-term evolution of a complex prone-to-fall cliff, Geophys. J. Int., 213, 1876-1897.

Del Gaudio, V., Muscillo, S. \& Wasowski, J., 2014. What we can learn about slope response to earthquakes from ambient noise analysis: an overview, Eng. Geol., 182, 182-200.

Gattinoni, P., Scesi, L., Arieni, L. \& Canavesi, M., 2012. The February 2010 large landslide at Maierato, Vibo Valentia, Southern Italy, Landslides, 9, 255-261.

Giraud, A., Antoine, P., Van Asch, T.W.J. \& Nieuwenhuis, J.D., 1991. Geotechnical problems caused by glaciolacustrine clays in the French Alps, Eng. Geol., 31, 185-195.

Guzzetti, F., 2000. Landslide fatalities and the evaluation of landslide risk in Italy, Eng. Geol., 58, 89-107.

Haghshenas, E., Bard, P.-Y. \& Theodulidis, N., 2008. Empirical evaluation of microtremor H/V spectral ratio, Bull. Earthq. Eng., 6, 75-108.

Hévin, G., Abraham, O., Pedersen, H.A. \& Campillo, M., 1998. Characterization of surface cracks with Rayleigh waves: a numerical model, $N D T$ E Int., 31, 289-297.

Hilloulin, B., Zhang, Y., Abraham, O., Loukili, A., Grondin, F., Durand, O. \& Tournat, V., 2014. Small crack detection in cementitious materials using nonlinear coda wave modulation, NDT E Int., 68, 98-104.

Hungr, O., Leroueil, S. \& Picarelli, L., 2014. The Varnes classification of landslide types, an update, Landslides, 11, 167-194.

Iverson, R.M., George, D.L., Allstadt, K., Reid, M.E., Collins, B.D., Vallance, J.W., Schilling, S.P. et al., 2015. Landslide mobility and hazards: implications of the 2014 Oso disaster, Earth planet. Sci. Lett., 412, 197208.

Jongmans, D., Bièvre, G., Schwartz, S., Renalier, F. \& Beaurez, N., 2009. Geophysical investigation of the large Avignonet landslide in glaciolacustrine clays in the Trièves area (French Alps), Eng. Geol., 109, 45-56.

Kramer, S.L., 1996. Earthquake Geotechnical Engineering, Prentice Hall.

Lacroix, P., Bièvre, G., Pathier, E., Kniess, U. \& Jongmans, D., 2018. Use of Sentinel-2 images for the detection of precursory motions before landslide failures, Remote Sens. Environ., 215, 507-516.

Lacroix, P. \& Helmstetter, A., 2011. Location of seismic signals associated with microearthquakes and rockfalls on the Séchilienne Landslide, French Alps, Bull. seism. Soc. Am., 101, 341, doi:10.1785/0120100110.

Larose, E., Carrière, S., Voisin, C., Bottelin, P., Baillet, L., Guéguen, P., Walter, F. et al., 2015a. Environmental seismology: what can we learn on earth surface processes with ambient noise?, J. appl. Geophys., 116, 62-74.

Larose, E., Obermann, A., Digulescu, A., Planès, T., Chaix, J.-F., Mazerolle, F. \& Moreau, G., 2015b. Locating and characterizing a crack in concrete with diffuse ultrasound: a four-point bending test, J. acoust. Soc. Am., 138, 232-241.

Larose, E., de Rosny, J., Margerin, L., Anache, D., Gouedard, P., Campillo, M. \& van Tiggelen, B., 2006. Observation of multiple scattering of $\mathrm{kHz}$ vibrations in a concrete structure and application to monitoring weak changes, Phys. Rev. E, 73, 016609, doi:10.1103/PhysRevE.73.016609.

Lévy, C., Baillet, L., Jongmans, D., Mourot, P. \& Hantz, D., 2010. Dynamic response of the Chamousset rock column (Western Alps, France), J. geophys. Res., 115, doi:10.1029/2009JF001606.

Lévy, C., Jongmans, D. \& Baillet, L., 2011. Analysis of seismic signals recorded on a prone-to-fall rock column (Vercors massif, French Alps), Geophys. J. Int., 186, 296-310.

Lobkis, O.I. \& Weaver, R.L., 2003. Coda-wave interferometry in finite solids: recovery of p-to-s conversion rates in an elastodynamic billiard, Phys. Rev. Lett., 90, 254302.

Mainsant, G., Jongmans, D., Chambon, G., Larose, E. \& Baillet, L., 2012. Shear-wave velocity as an indicator for rheological changes in clay materials: lessons from laboratory experiments, Geophys. Res. Lett., 39, L19301-L19301.

Méric, O., Garambois, S., Malet, J.-P., Cadet, H., Guéguen, P. \& Jongmans, D., 2007. Seismic noise-based methods for soft-rock landslide characterization, Bull. Soc. Géol. France, 178, 137.
Monjuvent, G., 1973. La transfluence Durance-Isère. Essai de synthèse du Quaternaire du bassin du Drac (Alpes françaises), Géol. Alpine, 49, 57118.

Moulin, C. \& Robert, Y., 2004, Le glissement de l'Harmalière sur la commune de Sinard, in Presented at the Proceedings of the workshop Ryskhydrogeo, Program Interreg III, p. 11, La Mure, France.

Mullen, R. \& Belytschko, T., 1982. Dispersion analysis of finite element semidiscretizations of the two-dimensional wave equation, Int. J. Numer. Methods Eng., 18, 11-29.

Nakamura, Y., 1989. A method for dynamic characteristics estimation of subsurface using microtremor on the ground surface, Railway Tech. Res. Instit., Quart. Rep., 30 (1), 25-33.

Olsen, K.B., Day, S.M. \& Bradley, C.R., 2003. Estimation of Q for longperiod ( $>2 \mathrm{sec}$ ) waves in the Los Angeles Basin, Bull. seism. Soc. Am., 93, 627-638.

Panizza, M., Pasuto, A., Silvano, S. \& Soldati, M., 1996. Temporal occurrence and activity of landslides in the area of Cortina d'Ampezzo (Dolomites, Italy), Int. J. Rock Mech. Min. Sci., 33, 311-326.

Peterson, J.R., 1993. Observations and modeling of seismic background noise, US Geological Survey.

Picarelli, L., Urciuoli, G., Ramondini, M. \& Comegna, L., 2005. Main features of mudslides in tectonised highly fissured clay shales, Landslides, 2, 15-30.

Poli, P., 2017. Creep and slip: Seismic precursors to the Nuugaatsiaq landslide (Greenland), Geophys. Res. Lett., 44, 8832-8836.

Provost, F., Malet, J.-P., Hibert, C., Helmstetter, A., Radiguet, M., Amitrano, D., Langet, N. et al., 2018. Towards a standard typology of endogenous landslide seismic sources, Earth Surf. Dyn., 6, 1059-1088.

RESIF/OMIV,2006. French Multidisciplinary Observatory of Versant Instabilities. RESIF - Réseau Sismologique et Géodésique Français., doi:10.15778/RESIF.MT.

Senfaute, G., Duperret, A. \& Lawrence, J.A., 2009. Micro-seismic precursory cracks prior to rock-fall on coastal chalk cliffs: a case study at Mesnil-Val, Normandie, NW France, Nat. Hazards Earth Syst. Sci., 9, $1625-1641$.

Sens-Schönfelder, C. \& Wegler, U., 2006. Passive image interferometry and seasonal variations of seismic velocities at Merapi Volcano, Indonesia, Geophys. Res. Lett., 33, doi:10.1029/2006GL027797.

Snieder, R., Grêt, A., Douma, H. \& Scales, J., 2002. Coda wave interferometry for estimating nonlinear behavior in seismic velocity, Science, 295, 2253-2255.

Spillmann, T., Maurer, H., Green, A.G., Heincke, B., Willenberg, H. \& Husen, S., 2007. Microseismic investigation of an unstable mountain slope in the Swiss Alps, J. geophys. Res., 112, doi:10.1029/2006JB004723.

Starr, A., Moore Jeffrey, R. \& Thorne Michael, S., 2015. Ambient resonance of Mesa Arch, Canyonlands National Park, Utah, Geophys. Res. Lett., 42, 6696-6702.

Tonnellier, A., Helmstetter, A., Malet, J.-P., Schmittbuhl, J., Corsini, A. \& Joswig, M., 2013. Seismic monitoring of soft-rock landslides: the SuperSauze and Valoria case studies, Geophys. J. Int., 193, 1515-1536.

Valentin, J., Capron, A., Jongmans, D., Baillet, L., Bottelin, P., Donze, F., Larose, E. \& Mangeney, A., 2017. The dynamic response of prone-to-fall columns to ambient vibrations: comparison between measurements and numerical modelling, Geophys. J. Int., 208, 1058-1076.

Van Asch, T.W.J., Van Beek, L.P.H. \& Bogaard, T.A., 2007. Problems in predicting the mobility of slow-moving landslides, Eng. Geol., 91, 4655.

Voisin, C., Garambois, S., Massey, C. \& Brossier, R., 2016. Seismic noise monitoring of the water table in a deep-seated, slow-moving landslide, Interpretation, 4, SJ67-SJ76.

Walter, M., Arnhardt, C. \& Joswig, M., 2012. Seismic monitoring of rockfalls, slide quakes, and fissure development at the Super-Sauze mudslide, French Alps, Eng. Geol., 128, 12-22.

Weaver, R.L., Hadziioannou, C., Larose, E. \& Campillo, M., 2011. On the precision of noise correlation interferometry, Geophys. J. Int., 185, 1384-1392.

Welch, P., 1967. The use of fast Fourier transform for the estimation of power spectra: a method based on time averaging over short, modified periodograms, IEEE Trans. Audio Electroacoust., 15, 70-73. 